\title{
Impact of Passive Heave Compensator on Offshore
}

\section{Lifting}

\author{
Arvind Keprate
}

Department of Mechanical and Structural Engineering and Material Science, University of Stavanger, Stavanger 4036, Norway

\begin{abstract}
Splash zone crossing of the structures with large horizontal surface (e.g. manifolds) and the structures having large weight variation in water and air (e.g. suction anchors) is a critical marine operation. This is due to the large slamming forces and added mass of the structure, which results in high dynamic loads on the crane. The solution to this could be attaching a PHC (Passive Heave Compensator) between the crane hook and the payload. This paper analyzes the deployment of a subsea manifold with and without PHC unit in North Sea at a water depth of approximately $370 \mathrm{~m}$. A detailed dynamic analysis is done for a seastate of $3 \mathrm{~m}$ significant wave height (Hs) over a range of zero up-crossing period (Tz) varying from 3s to 13s. For better understanding of the result analysis has been done in two stages. The first stage covers the lowering of manifold through the splash zone while second stage covers the seabed landing of the manifold. Based on the results of the analyses it is concluded that PHC tends to reduce the dynamic peak load on the crane. Besides this, it also mitigates the risk of slack wire situations during splash zone crossing of the payload. Furthermore, reduction in both landing velocity and crane tip velocity is also achieved by using a well-designed PHC unit.
\end{abstract}

Key words: PHC, dynamic analysis, Orcaflex.

\section{Introduction}

During the development of an offshore oil and gas field, marine operations play a very important role. One of the vital marine operations is offshore lifting of a structure, which consists of various operational phases: lifting in the air, lowering through the splash zone, lowering down to seabed and seabed landing [1]. Amongst the aforementioned phases, lowering of structures through splash zone is the most critical operational phase. This is because it is during this phase (i.e. splash zone crossing) where the maximum forces and lowest weather restrictions are expected to be found. Therefore, design loads must also be established for this phase of the operation [1].

While assessing the crane design loads, the dynamic loads due to operational motion must be accounted for. This is achieved by multiplying the working/static load by a dynamic factor $(\psi)$, which takes into account the inertia forces and shock [2]. Also due to added

Corresponding author: Arvind Keprate, research fellow, research fields: offshore piping. E-mail: arvind.keprate@uis.no. dynamics in the rough sea-state, the working load of an offshore crane depends on the significant wave height (Hs). For e.g. a typical crane SWL (Safe Working Load) is reduced by $30 \%$ at $2 \mathrm{~m}$ Hs and by $50 \%$ at $3 \mathrm{~m}$ Hs [3].

To reduce the dependency of working load of the crane on Hs and to increase its working load capacity, a PHC (Passive Heave Compensation) unit is attached between the crane hook and the payload. This manuscript briefly explains PHC and its impact on offshore lifting by performing dynamic analysis on Orcaflex. Section 2 of the paper defines PHC and briefly discusses the working principle, efficiency and application of the PHC. Thereafter, in section 3 a case study demonstrating the installation analyses of subsea manifold using Orcaflex has been done. Finally, a suitable conclusion is presented in section 4 .

\section{Passive Heave Compensator}

\subsection{Definition}

PHC is "an offshore equipment, generally connected 
between the crane hook and the payload, such that it stores the energy from waves influencing the payload and dissipate it later" [3]. A general PHC unit consists of a spring-damper system constructed with cylinder, piston, nozzles and accumulator as depicted in Fig. 1 [4]. The cylinder is filled with hydraulic oil, while the accumulator is filled with Nitrogen. These units have a certain available stroke limit, which should not exceed during the lifting operation. If exceeded, it may cause large peak loads thereby causing failure of the hoisting system [5].

\subsection{Working Principle}

For a crane mounted on the floating vessel the dynamic loads due to operational motion are taken into consideration by multiplying the working load by a dynamic factor $(\psi)$. The dynamic factor (also called Dynamic Amplification Factor-DAF) takes into account the inertia force and shock and is given by Ref. [2]:

$$
\left.\psi=1+V_{r} * \sqrt{(} \frac{C}{W * g}\right)
$$

The load on the crane wire during offshore lifting operation is equal to the dynamic load $\left(F_{d}\right)$, which is equal to $\psi * W$. The dynamic load $\left(F_{d}\right)$ can be reduced by following ways:

Reduce working/static load $(W)$.

Reduce $V r$, which implies waiting for lower waves or working in the lower wave condition.

Reduce $C$.

If we intend to reduce $F_{d}$ by reducing option 1 and 2; then we are compromising on productivity. Alternatively, by providing a soft link or a device having low stiffness between the crane hook and the payload, reduction in $C$ is achieved, which ultimately leads to mitigation of $F_{d}$. This forms the bases of PHC whose working principle is explained next.

The PHC is in principle a pure spring damper system, which does not require input of energy during operation [5].As shown in Fig. 1, the payload is attached to lower end of the piston rod, which causes it to extend. As the piston rod extends, it forces the oil in the cylinder to flow into the accumulator via nozzle. The nozzle restricts the flow and provide necessary dampening effect, while the gas that is being compressed by upward motion of piston in accumulator, provides the spring effect. Thus, the combination of spring and dampening effect isolates the payload from the wave motion and provides the required heave compensation [6].

The stiffness of the compensator is proportional to the gas pressure inside the accumulator, which varies with the motion of the piston [7]. Moreover, the hydraulic dampening force for PHC is given by Ref. [2]:

$$
F_{d}=A_{k}^{3} * \frac{\rho}{2} *\left(\frac{1}{\alpha * A} * S_{v}\right)^{\wedge} 2
$$

The aforementioned equation depicts that $F_{d}$ is proportional to square of stroking velocity. Hence, increase in stroke velocity, which refers to increased heave motion increases $F_{d}$ as well. However, it must be noted that dampening and stiffness characteristics can be changed to suit different lifts. This is achieved by changing nozzles, oil level or accumulator pressure [8].

\subsection{Efficiency}

The ratio between the response of the lifted object and the excited motion is expressed through a complex transfer function [5]:

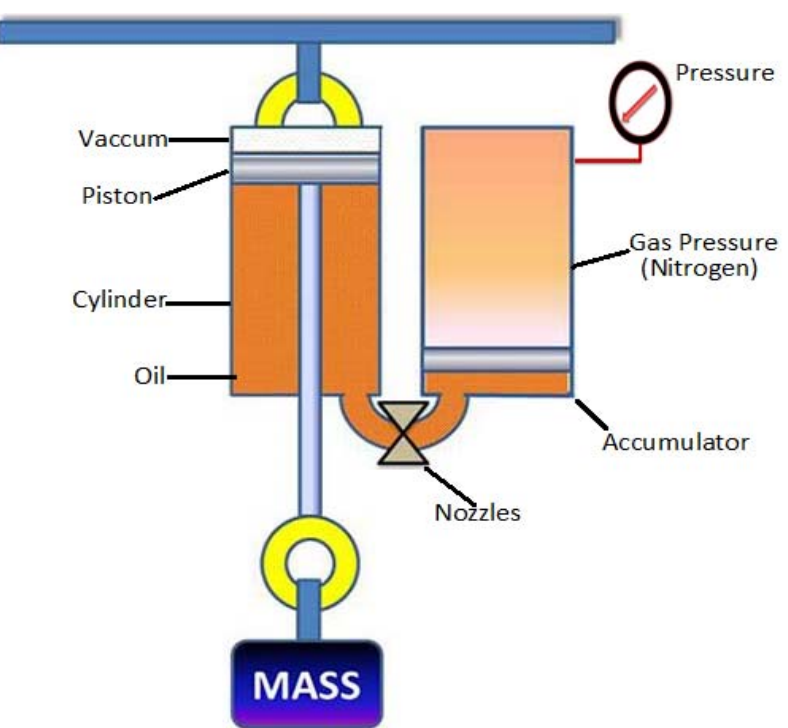

Fig. 1 Schematic of typical PHC. 


$$
\frac{\eta_{3}}{\eta_{3 T}}=G(\omega)
$$

Efficiency of the PHC in terms of the complex transfer function is given as:

$$
e=1-|G(\omega)|
$$

Where $G(\omega)$ is transmissibility and $e$ is efficiency of the PHC, which tells us whether PHC will contribute positively during offshore lifting operation or not. Furthermore, based on the efficiency formulae it is stated that efficient heave compensation is obtained when:

The natural frequency, $\omega o$ is as low as possible.

Both drag forces and added mass are large.

Stiffness of the PHC is low.

Heave compensator damping is low enough to avoid resonance.

Both wave period and mass density of the payload are low as shown in Fig. 2.

\subsection{Offshore Application}

During the offshore lifting operation, PHC is connected between the crane hook and the payload in order to reduce the dynamic load on the hoisting system and the crane tip. Some of its application areas are:

(a) Splash zone lifts: As the AHC (Active Heave Compensator) does not function well in the splash zone, so PHC is used as the compensating device. The PHC absorbs the huge dynamic forces on payload during splash zone crossing, thus reducing the dynamic loads on the crane tip and the hoisting system. The PHC also reduces the chances of slack wire during splash zone lifting; nevertheless, if the slack occurs in the wire then the piston rod extends to compensate this removal of slack and absorbs the snap load resulting from this tautening process.

(b) Seabed landing: The PHC is used to attain reduction in landing velocity of the structure on the seabed. This is important because generally the landing velocity of the payload is very close to the hoisting velocity $(V c)$ of the winch, which is assumed to be 0.5 $\mathrm{m} / \mathrm{s}$, if it's value is unknown [5]. Landing at such high velocities causes damage to the seabed structure. Furthermore, the structure may have tendency to rebound on hitting the seabed, which may damage the crane. Both of these detrimental effects are avoided by using well designed PHC unit.

(c) Resonance avoidance: During offshore lifting the crane wire stiffness changes with the water depth, which leads to the change in frequency of the hoisting and payload system. If during this lowering process the period of crane tip movement matches with the frequency of the hoisting and payload system, resonance may occur. Such a situation must be avoided,

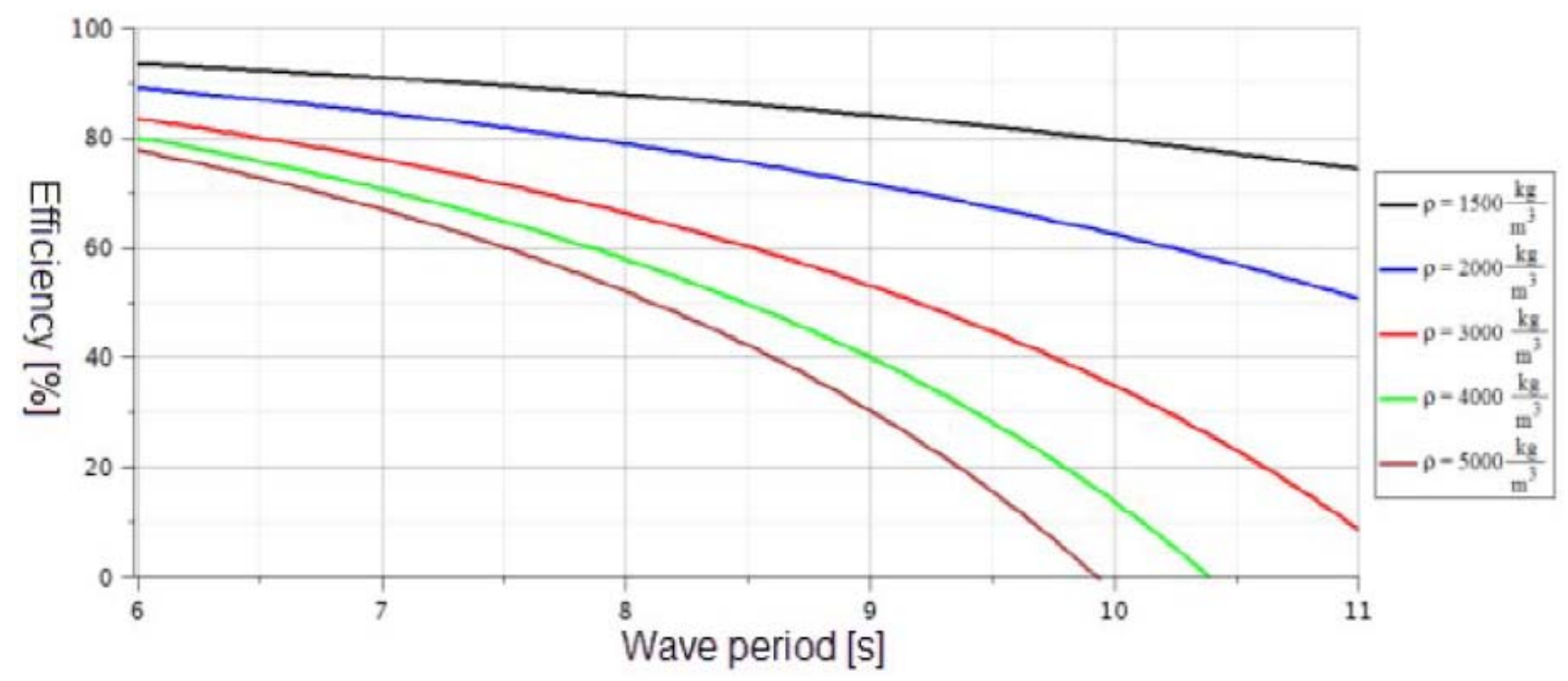

Fig. 2 Efficiency of typical PHC[3]. 
as resonance leads to large dynamic loads on the entire system, which in the worst case may cause failure of the hoisting system. However, resonance is avoided by adding a PHC between the crane hook and the payload, as PHC increases the system frequency to a level which cannot be matched by the wave frequencies [3]

\section{Illustrative Case Study}

\subsection{Purpose and Scope}

The purpose of the analysis is to compare the offshore lifting operations with and without PHC; thereby proving that by using a PHC between the crane hook and payload, dynamic load on the hoisting system and the crane is reduced. Furthermore, it is intended to show that crane tip velocities and landing velocity of the payload are also reduced by the use of PHC.

The analysis is done using Orcaflex to assess the operators viability in the Hs of $3 \mathrm{~m}$ over a range of $\mathrm{Tz}$ varying from $3 \mathrm{~s}$ to $13 \mathrm{~s}$ and using the methodology mentioned in Ref. [5]. The crane wire hoisting velocity $V c$ of $0.5 \mathrm{~m} / \mathrm{s}$ Ref. [5] is used in the analysis and vessel heading is assumed to be restricted within 15 degrees of head sea. For the sake of simplicity, the analysis is divided into two phases:

(a) First phase-lowering through splash zone: In this part of the operation the governing forces and lowest weather conditions are expected to be found. Hence, this part of operation is very critical from design point of view. Analysis is done to check:

(1) Maximum and minimum crane wire tension (with and without PHC).

(2) Maximum and minimum lifting slings tension (with and without PHC).

(3) Identifying slack in lifting slings (with and without PHC).

(b) Second phase-landing on seabed: The crane wire tension is expected to be lower during this part of operation as compared to lowering through splash zone. During this phase the utility of PHC is depicted as a device which reduces the landing velocity of structure on seabed. Analysis is done to check:

(1) Maximum and minimum crane wire tension (with and without PHC).

(2) Maximum crane hook velocities (with and without PHC).

The maximum and minimum value of tension and velocity is found using a Gumbel distribution.

\subsection{Environmental Conditions}

For installation analysis of the manifold, an assumed site in the North Sea in water depth of $370 \mathrm{~km}$ is chosen. The JONSWAP wave spectrum is used in the analysis and only one wave direction is considered in the analysis. During the analysis it is assumed that the vessel is free to weather vane during all operations except for the landing operation. Furthermore, the analysis is run for head seas ( 0 degrees) \pm 15 degrees (-15 degrees are waves coming from starboard and +15 degrees are waves coming from port as shown in Fig. 3). Hence, the analysis is done for the wave directions 165 degree, 180 degree and 195 degree.

The analysis does not include shielding or refraction of waves. Therefore, results for waves coming from -15 degrees are thus expected to be conservative, because in real life the vessel has a shielding effect, which calms the water surface in the area, where the template crosses the water surface. Furthermore, short term wave condition as defined in Ref. [5] is used and the analysis is performed for $\mathrm{Hs}=3 \mathrm{~m}$ and $\mathrm{Tz}$ varying from $3 \mathrm{~s}$ to $13 \mathrm{~s}$.

\subsection{Analysis Model}

The model for our case study is comprised of the IV (installation vessel), a subsea manifold (payload), four lifting slings, crane winch wire and the PHC. The Orcaflex model of IV and associated information about loading condition and displacement RAOs are taken from one of the engineering contractors. Since, the weight of the manifold is less than $1 \%$ of the total mass of the vessel, therefore, it is assumed that manifold has very less influence on the vessels motion. 


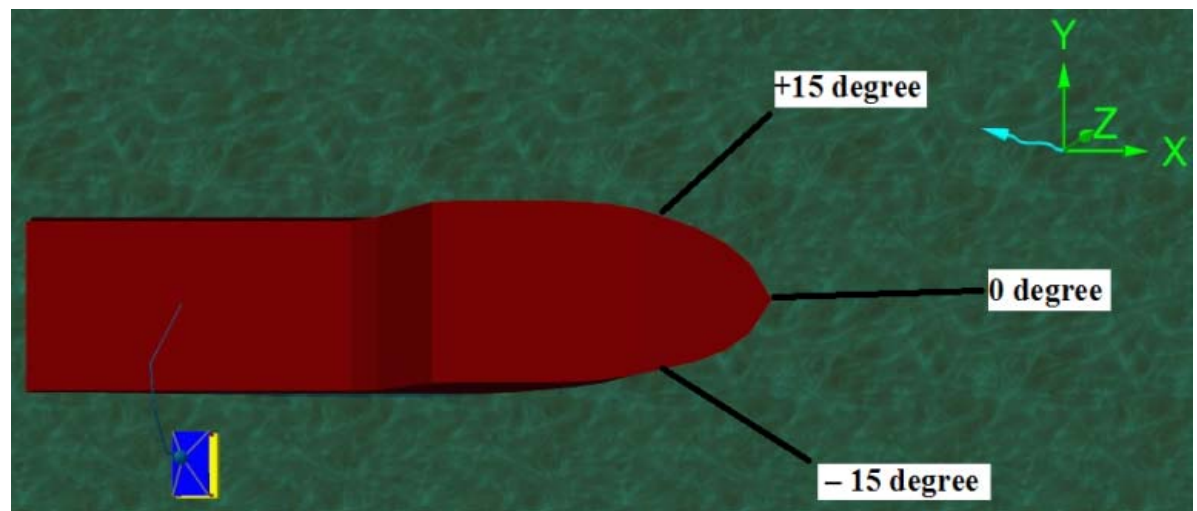

Fig. 3 Definition of wave direction.

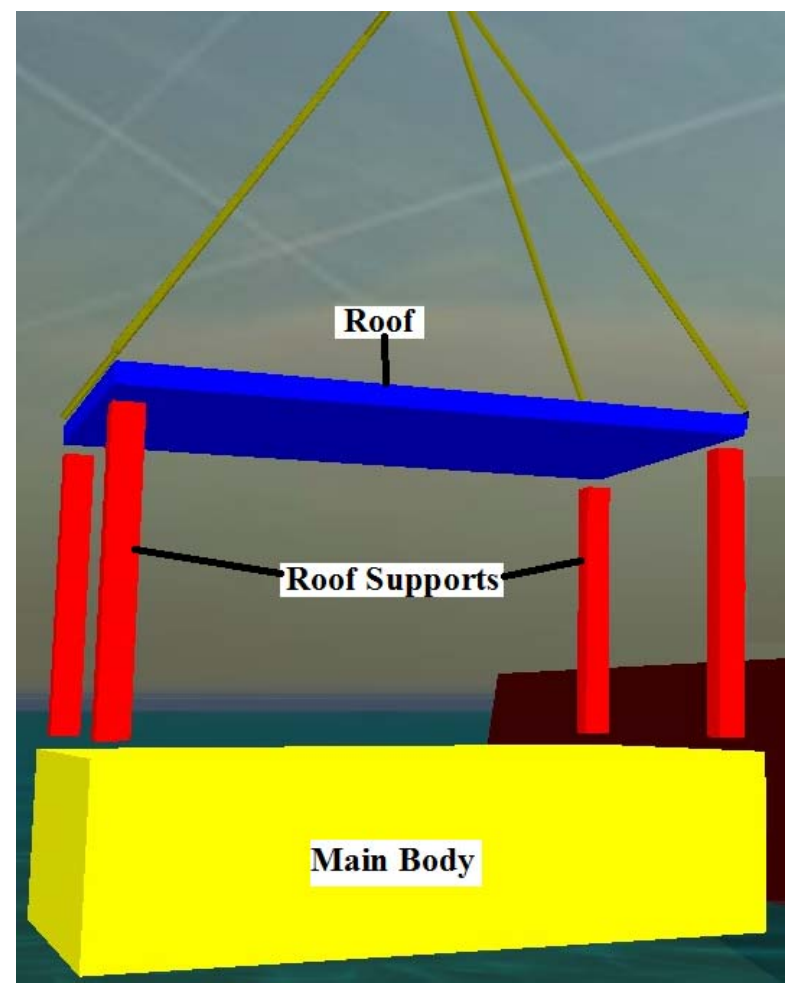

Fig. 4 Orcaflex manifold model.

The manifold is a complex structure consisting of many parts with varying hydrodynamic properties. The dimensions of manifold are assumed $12 \mathrm{~m} * 6 \mathrm{~m} * 7 \mathrm{~m}$, with assumed mass of 90 tons and submerged weight of 78 tons. For the modeling process in Orcaflex, the manifold is divided into various parts as shown in Fig. 4 and listed below:

(a) The main body where all piping, valves etc. are present (80 tons).

(b) The roof (8 tons).

(c) 4 roof support structures ( 0.5 tons each).
It is assumed in the analysis that the main body and the roof are hydrodynamically independent to each other. Furthermore, based on guidance note given in Ref. [5] it is assumed that the roof support structures does not contribute to any vertical hydrodynamic forces as they are in the shadow of the roof and the main body.

The Orcaflex 3-D model of the PHC is depicted in Fig. 5.

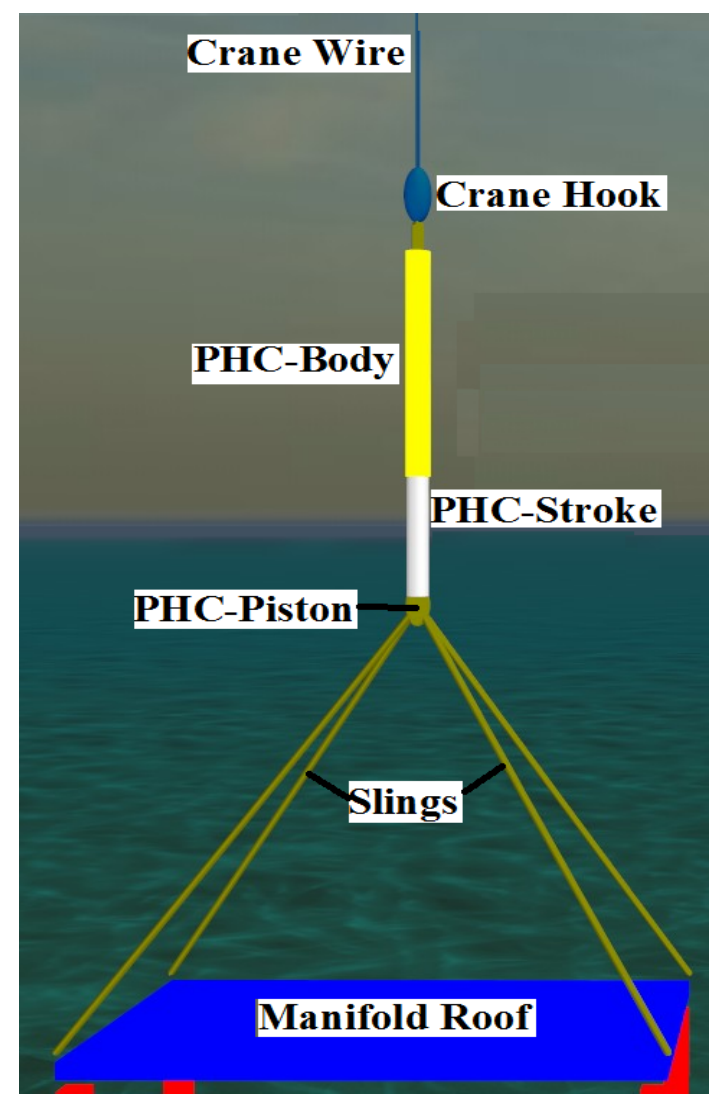

Fig. 5 Orcaflex PHC model. 
The entire model of the PHC along with the associated stiffness and damping values are taken from the crane master calculation sheets.

\subsection{Result}

A substantially large number of simulation runs are performed for each sea state in order to obtain realistic amplitudes on the peak forces. For our case, a 3-hoursimulation run is done using a pre-processing excel spreadsheet provided in the Orcaflex software. After this post-processing of results is done using Gumbel distribution for a PNE (probability of non-exceedance) of 95\% using the post-processing, excel spreadsheet provided in the Orcaflex software.

The excel sheets used for pre-processing and post-processing during analysis were taken from Ref. [9], and as a reference are provided in Appendix. Finally, the results are presented separately for the two phases of lifting operation. However, for both the operations, dynamic simulation simulates crane wire pay-out, whose lowering velocity is set to $0.5 \mathrm{~m} / \mathrm{s}$ [5].

\subsubsection{Splash Zone Result}

The analysis starts with the manifold hanging completely in air and then being lowered in air, followed by lowering through the splash zone as depicted in Fig. 6. The simulation continues until the entire manifold is submerged completely in the water.

The results are summarized in Table 1 and 2, with the maximum values highlighted by red colour.

By comparing the values in Table 1 and 2 it is inferred that the PHC leads to reduction of maximum crane wire tension during the splash zone crossing. The same trend is followed by the slings. However, it is clearly seen that the variation in crane wire tension for longer Tz periods is smaller when compared to smaller Tz periods. This indicates that the efficiency of PHC decreases for longer Tz periods as depicted in Fig. 2. Hence, it is beneficial to use PHC only for low to medium $\mathrm{Tz}$ periods. The comparative results are also presented in the time series graph shown in Fig. 7.

Fig. 7 depicts that during lowering operation in the air, only the dry weight of the manifold and forces due to crane tip accelerations are acting on the structure. Due to cancelation of stiffness and dampening effect of the PHC by its weight the crane wire tension for both the cases is nearly the same for this phase. However,

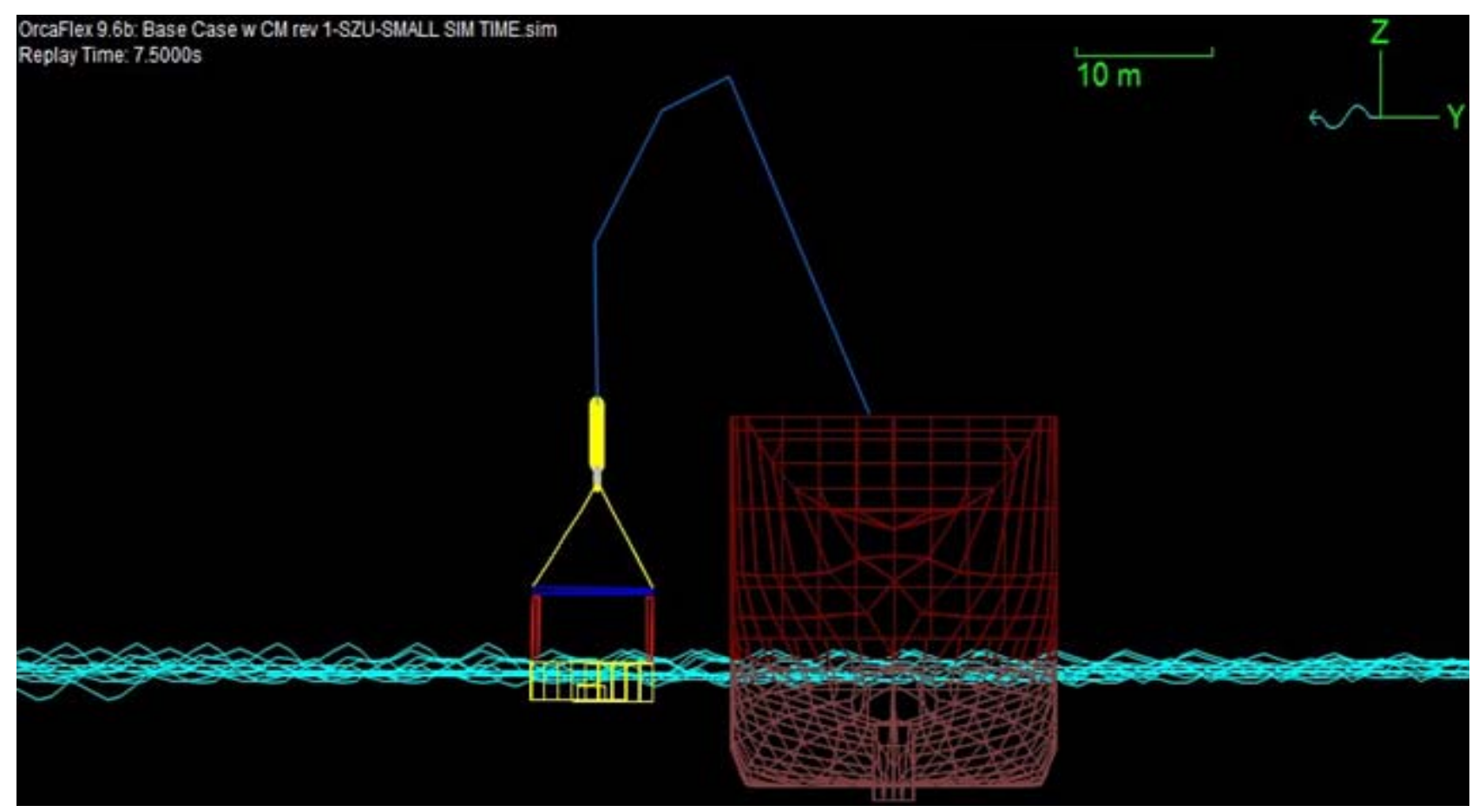

Fig. 6 Wireframe model for lowering through splash zone. 
Table 1 Splash zone crossing result without PHC (Hs = 3 m).

\begin{tabular}{|c|c|c|c|c|c|c|c|c|c|c|c|c|}
\hline \multirow{6}{*}{$165 \mathrm{deg}$} & $\mathrm{Tz}(\mathrm{s})$ & 3 & 4 & 5 & 6 & 7 & 8 & 9 & 10 & 11 & 12 & 13 \\
\hline & Max Crane Wire Tension [kN] & 2108.22 & 2033.46 & 2113 & 1913.2 & 1530.4 & 1496.6 & 1255.4 & 1130.4 & 1073.3 & 1099.3 & 1051.01 \\
\hline & Max Sling\#1 Tension[kN] & 104.798 & 626.991 & 650.668 & 607.49 & 480.58 & 458.38 & 376.29 & 352.01 & 343.58 & 356.59 & 329.043 \\
\hline & Max Sling\#2 Tension[kN] & 853.265 & 714.754 & 648.322 & 564.53 & 477.04 & 434.97 & 359.19 & 325.66 & 308.93 & 311.5 & 289.279 \\
\hline & Max Sling\#3 Tension[kN] & 840.533 & 613.786 & 787.226 & 584.43 & 463.44 & 458.53 & 404.47 & 349.73 & 333.59 & 339.58 & 328.96 \\
\hline & Max Sling\#4 Tension[kN] & 916.966 & 684.142 & 653.25 & 596.04 & 469.53 & 446.35 & 382.41 & 333.7 & 317.3 & 336.11 & 301.515 \\
\hline \multirow{6}{*}{180 deg } & Tz (s) & 3 & 4 & 5 & 6 & 7 & 8 & 9 & 10 & 11 & 12 & 13 \\
\hline & Max Crane Wire Tension [kN] & 2446.88 & 2075.53 & 1998.39 & 1851.6 & 1481.1 & 1408.3 & 1228.2 & 1141.2 & 1069.5 & 1055.4 & 1003.08 \\
\hline & Max Sling\#1 Tension[kN] & 788.047 & 759.053 & 656.572 & 562.15 & 488.66 & 434.31 & 362.48 & 343.03 & 334.02 & 333.24 & 319.075 \\
\hline & Max Sling\#2 Tension[kN] & 860.181 & 739.558 & 648.692 & 582.87 & 463.94 & 405.17 & 358.09 & 327.76 & 309.22 & 290.47 & 284.558 \\
\hline & Max Sling\#3 Tension[kN] & 791.772 & 690.461 & 688.558 & 538.33 & 447.42 & 446.42 & 388.11 & 361.39 & 334 & 321.2 & 319.977 \\
\hline & Max Sling\#4 Tension[kN] & 837.303 & 751.136 & 586.045 & 546.28 & 421.64 & 409.88 & 379.86 & 343.98 & 321.46 & 322.42 & 308.106 \\
\hline \multirow{6}{*}{$195 \mathrm{deg}$} & Tz (s) & 3 & 4 & 5 & 6 & 7 & 8 & 9 & 10 & 11 & 12 & 13 \\
\hline & Max Crane Wire Tension [kN] & 2183.68 & 2189.79 & 1761.38 & 1521.7 & 1388 & 1267.2 & 1191.9 & 1187.3 & 992.96 & 1036.2 & 991.844 \\
\hline & Max Sling\#1 Tension[kN] & 755.08 & 718.967 & 535.061 & 484.95 & 417.76 & 404.83 & 382.92 & 370.94 & 310.9 & 329.83 & 310.851 \\
\hline & Max Sling\#2 Tension[kN] & 863.198 & 731.064 & 539.398 & 474.35 & 416.41 & 385.32 & 351.85 & 342.9 & 282.43 & 281.97 & 274.787 \\
\hline & Max Sling\#3 Tension[kN] & 762.68 & 771.99 & 568.62 & 466 & 404.3 & 418.8 & 389.9 & 352.7 & 315.4 & 330.5 & 317.31 \\
\hline & Max Sling\#4 Tension [kN] & 879.35 & 767.72 & 580.8 & 479.1 & 432 & 390.7 & 358.7 & 357.5 & 302.3 & 311 & 292.16 \\
\hline
\end{tabular}

Table 2 Splash zone crossing result with PHC (Hs = 3 m).

\begin{tabular}{|c|c|c|c|c|c|c|c|c|c|c|c|c|}
\hline \multirow{6}{*}{ 165deg } & Tz (s) & 3 & 4 & 5 & 6 & 7 & 8 & 9 & 10 & 11 & 12 & 13 \\
\hline & Max Crane Wire Tension [kN] & 1586.7 & 1346.1 & 1685.8 & 1313.9 & 1202.4 & 1177 & 1085.1 & 1058.6 & 1015.3 & 1006.3 & 970.6 \\
\hline & Max Sling\#1 Tension[kN] & 537.2 & 463.8 & 614 & 469.9 & 396.9 & 389.1 & 363.1 & 337.6 & 323.8 & 325.6 & 312.4 \\
\hline & Max Sling\#2 Tension[kN] & 469.232 & 387.35 & 539.51 & 366.5 & 339.627 & 321.91 & 303.711 & 299.49 & 276.839 & 280.83 & 265.509 \\
\hline & Max Sling\#3 Tension[kN] & 536.605 & 444.48 & 97.22 & 444.95 & 383.212 & 367.72 & 364.34 & 346.33 & 325.642 & 330.45 & 319.234 \\
\hline & Max Sling\#4 Tension $[\mathrm{kN}]$ & 498.534 & 410.64 & 557.71 & 395.13 & 365.311 & 357.35 & 330.57 & 324.03 & 302.162 & 310.13 & 298.719 \\
\hline \multirow{6}{*}{ 180deg } & $\mathrm{Tz}(\mathrm{s})$ & 3 & 4 & 5 & 6 & 7 & 8 & 9 & 10 & 11 & 12 & 13 \\
\hline & Max Crane Wire Tension $[\mathrm{kN}]$ & 1486.4 & 1384.9 & 1733.2 & 1311.5 & 1063.9 & 1094.1 & 1021 & 998.1 & 949.4 & 938.2 & 954.9 \\
\hline & Max Sling\#1 Tension $[\mathrm{kN}]$ & 514.8 & 488.7 & 587.1 & 498.3 & 373.2 & 352.6 & 336.8 & 323.5 & 308.2 & 303.2 & 308 \\
\hline & Max Sling\#2 Tension[kN] & 471.85 & 422.72 & 514.2 & 396.95 & 306.662 & 300.09 & 285.865 & 275.21 & 262.23 & 258.29 & 262.479 \\
\hline & Max Sling\#3 Tension[kN] & 484.728 & 488.54 & 582.14 & 475.4 & 355.63 & 362.24 & 329.424 & 323.03 & 304.586 & 302.52 & 307.479 \\
\hline & Max Sling\#4 Tension[kN] & 481.639 & 457.62 & 519.15 & 416.6 & 348.632 & 334.84 & 304.791 & 303.13 & 285.099 & 283.74 & 287.727 \\
\hline \multirow{6}{*}{ 195deg } & Tz (s) & 3 & 4 & 5 & 6 & 7 & 8 & 9 & 10 & 11 & 12 & 13 \\
\hline & Max Crane Wire Tension [kN] & 1497.21 & 1248 & 1446.7 & 1253.9 & 1056.93 & 1146.8 & 1058.1 & 1005.3 & 982.454 & 967.42 & 984.152 \\
\hline & Max Sling\#1 Tension[kN] & 478.5 & 416.3 & 495.3 & 423.9 & 367.2 & 374.9 & 340.7 & 325.3 & 318.6 & 314.4 & 319.2 \\
\hline & Max Sling\#2 Tension[kN] & 450.078 & 375.79 & 410.21 & 356.18 & 325.182 & 328.87 & 290.672 & 280.63 & 275.135 & 266.79 & 268.777 \\
\hline & Max Sling\#3 Tension[kN] & 480.01 & 412.1 & 489.8 & 422.4 & 356.87 & 369.9 & 348.69 & 325 & 316.72 & 313.5 & 322.96 \\
\hline & Max Sling\#4 Tension $[\mathrm{kN}]$ & 460.34 & 383.4 & 443.3 & 393.8 & 334.03 & 345.4 & 322.32 & 305.6 & 303.21 & 292 & 299.16 \\
\hline
\end{tabular}






Fig. 7 Time history graph showing crane wire tension with and without PHC (Hs = 3 m).

Table 3 Splash zone crossing result for slings without PHC (Hs = 3 m).

\begin{tabular}{|c|c|c|c|c|c|c|c|c|c|c|c|c|}
\hline \multirow{5}{*}{ 165deg } & $\mathrm{Tz}(\mathrm{s})$ & 3 & 4 & 5 & 6 & 7 & 8 & 9 & 10 & 11 & 12 & 13 \\
\hline & Minimum Sling\#1 Tension[kN] & -29.9 & -33.4 & -17.0 & 21.4 & 51.9 & 95.6 & 106.2 & 143.4 & 158.7 & 161.5 & 168.4 \\
\hline & Minimum Sling\#2 Tension[kN] & -18.5 & -20.4 & -13.5 & 14.8 & 30.0 & 75.2 & 82.3 & 98.2 & 120.4 & 113.3 & 123.6 \\
\hline & Minimum Sling\#3 Tension[kN] & -28.3 & -31.9 & -14.7 & 31.9 & 53.2 & 100.4 & 114.1 & 136.6 & 163.3 & 162.6 & 168.8 \\
\hline & Minimum Sling\#4 Tension[kN] & -26.1 & -28.0 & -13.4 & 4.0 & 50.5 & 87.5 & 86.4 & 121.4 & 141.4 & 138.8 & 151.1 \\
\hline \multirow{5}{*}{ 180deg } & $\mathrm{Tz}(\mathrm{s})$ & 3 & 4 & 5 & 6 & 7 & 8 & 9 & 10 & 11 & 12 & 13 \\
\hline & Minimum Sling\#1 Tension[kN] & -28.3 & -28.0 & -36.9 & 15.9 & 73.2 & 89.1 & 109.8 & 155.6 & 170.0 & 174.1 & 184.6 \\
\hline & Minimum Sling\#2 Tension[kN] & -18.2 & -13.0 & -23.5 & -4.7 & 66.7 & 59.3 & 62.2 & 113.0 & 135.6 & 133.0 & 138.8 \\
\hline & Minimum Sling\#3 Tension[kN] & -17.8 & -18.3 & -28.1 & -10.0 & 82.6 & 86.8 & 112.5 & 155.4 & 169.8 & 178.5 & 181.9 \\
\hline & Minimum Sling\#4 Tension[kN] & -12.0 & -19.5 & -32.0 & -3.0 & 68.2 & 79.8 & 92.1 & 133.7 & 150.0 & 158.5 & 163.2 \\
\hline \multirow{5}{*}{ 195deg } & $\mathrm{Tz}(\mathrm{s})$ & 3 & 4 & 5 & 6 & 7 & 8 & 9 & 10 & 11 & 12 & 13 \\
\hline & Minimum Sling\#1 Tension[kN] & -24.8 & -35.2 & -7.1 & 8.3 & 107.1 & 111.2 & 136.7 & 158.5 & 158.0 & 189.6 & 168.8 \\
\hline & Minimum Sling\#2 Tension[kN] & -13.0 & -20.6 & 8.7 & 3.6 & 64.6 & 75.5 & 105.2 & 117.3 & 115.6 & 142.9 & 136.0 \\
\hline & Minimum Sling\#3 Tension[kN] & -22.0 & -33.5 & -12.1 & 24.0 & 109.9 & 118.5 & 138.9 & 156.5 & 161.7 & 191.1 & 181.2 \\
\hline & Minimum Sling\#4 Tension[kN] & -17.4 & -27.1 & -4.2 & 24.6 & 95.9 & 96.6 & 123.0 & 141.3 & 137.3 & 178.0 & 151.7 \\
\hline
\end{tabular}

during the splash zone lowering, manifold experiences the highest force variations due to the transient hydrodynamic effects. Thus, the time series shows quick changes in crane wire tension. In this zone, PHC reduces both the peak loads and fluctuations in crane wire tension, thereby rendering its utility. However, as soon as the manifold is fully submerged in sea, the time series becomes smaller indicating that the mean force in the crane wire is reduced due to the buoyancy of the structure.

The same trend is observed in the time series of the lifting sling forces, however, the slings experience slack. The slack criteria used for analysis is $F_{\text {hyd }} \leq 0.9 * F_{\text {ministatic }}$ [4]. As the assumed submerged weight $\left(F_{\text {min.static }}\right)$ of module is $765 \mathrm{kN}$ (78 tons), so by using the above criteria, if the minimum tension in the 
slings is below $10 \%$ of $765 \mathrm{kN}$ (i.e. $76.5 \mathrm{kN}$ ) the slings are assumed to be slacked. The slacked slings are shown as green blocks in Tables 3 and 4.

Table 3 indicates a lot of slacked slings for lower to medium Tz periods. It is recommended that slacks are avoided during splash zone crossing of the manifold, as slacked slings cause huge snap forces on the hoisting system and crane tip. Tables 3 and 4 depict that PHC leads to complete reduction in slack wires for Tz period of $3 \mathrm{~s}$ and $4 \mathrm{~s}$; hence indicating its high efficiency at low periods. However, the PHC has led to slacking of wire at higher periods. This is not an issue, as the piston rod of the PHC extends to compensate this removal of the slack and absorbs the snap load resulting from the tautening process, thereby protecting the hoisting system from huge snap forces.

Table 4 Splash zone crossing result for slings with PHC (Hs = 3 m).

\begin{tabular}{|c|c|c|c|c|c|c|c|c|c|c|c|c|}
\hline \multicolumn{13}{|c|}{ With PHC: Splash Zone } \\
\hline \multirow{5}{*}{$165 \mathrm{deg}$} & $\mathrm{Tz}(\mathrm{s})$ & 3 & 4 & 5 & 6 & 7 & 8 & 9 & 10 & 11 & 12 & 13 \\
\hline & Minimum Sling\#1 Tension $[\mathrm{kN}]$ & 138.7 & 129.8 & -33.7 & 12.9 & 57.2 & 27.3 & 32.3 & 60.3 & 81.1 & 72.6 & 125.6 \\
\hline & Minimum Sling\#2 Tension[kN] & 103.4 & 95.1 & -43.9 & -3.6 & 35.0 & 6.4 & 15.7 & 34.3 & 63.3 & 44.5 & 90.8 \\
\hline & Minimum Sling\#3 Tension $[\mathrm{kN}]$ & 144.5 & 132.4 & -36.5 & 9.6 & 49.4 & 20.3 & 25.2 & 52.2 & 73.5 & 65.3 & 109.4 \\
\hline & Minimum Sling\#4 Tension[kN] & 128.1 & 128.0 & -23.2 & 11.2 & 52.5 & 25.1 & 28.6 & 52.4 & 82.8 & 63.2 & 103.3 \\
\hline \multirow{5}{*}{180 deg } & $\mathrm{Tz}(\mathrm{s})$ & 3 & 4 & 5 & 6 & 7 & 8 & 9 & 10 & 11 & 12 & 13 \\
\hline & Minimum Sling\#1 Tension $[\mathrm{kN}]$ & 161.3 & 128.4 & 4.3 & 26.3 & 103.4 & 94.3 & 127.4 & 144.7 & 188.5 & 158.0 & 200.5 \\
\hline & Minimum Sling\#2 Tension $[\mathrm{kN}]$ & 121.7 & 86.8 & -10.9 & 28.1 & 74.6 & 65.1 & 95.6 & 127.8 & 149.4 & 122.6 & 159.4 \\
\hline & Minimum Sling\#3 Tension $[\mathrm{kN}]$ & 164.1 & 143.9 & 9.8 & 19.3 & 94.2 & 88.5 & 122.1 & 138.9 & 187.7 & 138.7 & 196.9 \\
\hline & Minimum Sling\#4 Tension $[\mathrm{kN}]$ & 149.4 & 124.2 & 8.6 & 44.5 & 90.6 & 85.4 & 116.3 & 154.1 & 175.0 & 130.8 & 183.8 \\
\hline \multirow{5}{*}{$195 \mathrm{deg}$} & Tz (s) & 3 & 4 & 5 & 6 & 7 & 8 & 9 & 10 & 11 & 12 & 13 \\
\hline & Minimum Sling\#1 Tension $[\mathrm{kN}]$ & 162.4 & 149.0 & 86.0 & 43.7 & 74.2 & 43.8 & 74.5 & 91.5 & 112.9 & 124.4 & 122.0 \\
\hline & Minimum Sling\#2 Tension[kN] & 103.5 & 100.6 & 54.1 & 26.7 & 45.6 & 19.2 & 46.1 & 62.1 & 74.6 & 91.1 & 90.1 \\
\hline & Minimum Sling\#3 Tension $[\mathrm{kN}]$ & 161.1 & 168.4 & 58.7 & 34.9 & 65.3 & 36.2 & 50.3 & 80.5 & 108.1 & 118.5 & 116.2 \\
\hline & Minimum Sling\#4 Tension[kN] & 137.5 & 148.2 & 62.2 & 36.8 & 60.9 & 37.7 & 49.6 & 77.2 & 97.4 & 111.2 & 110.6 \\
\hline
\end{tabular}

Table 5 Result for seabed landing without PHC (Hs = 3 m).

\begin{tabular}{|c|c|c|c|c|c|c|c|c|c|c|c|c|}
\hline \multirow{3}{*}{$165 \mathrm{deg}$} & Tz & 3 & 4 & 5 & 6 & 7 & 8 & 9 & 10 & 11 & 12 & 13 \\
\hline & Max Crane Wire Tension [kN] & 770.94 & 963.62 & 1230 & 1098.2 & 1168.2 & 1228.8 & 968.7 & 1001.3 & 1048.5 & 955.2 & 1020.3 \\
\hline & Max Crane Tip Velocity $[\mathrm{m} / \mathrm{s}]$ & 0.8252 & 2.9514 & 4.034 & 3.484 & 2.3176 & 2.8277 & 2.26 & 1.6884 & 1.7452 & 1.695 & 2.0857 \\
\hline \multirow{3}{*}{$180 \mathrm{deg}$} & Tz & 3 & 4 & 5 & 6 & 7 & 8 & 9 & 10 & 11 & 12 & 13 \\
\hline & Max Crane Wire Tension [kN] & 762.25 & 889.39 & 1261 & 1068.5 & 1135.1 & 1113.4 & 958 & 929.61 & 902.27 & 887.5 & 936.3 \\
\hline & Max Crane Tip Velocity [m/s] & 0.8098 & 2.1271 & 2.844 & 2.4553 & 2.031 & 2.3911 & 1.802 & 1.3984 & 1.5303 & 1.496 & 1.6105 \\
\hline \multirow{3}{*}{$195 \mathrm{deg}$} & Tz & 3 & 4 & 5 & 6 & 7 & 8 & 9 & 10 & 11 & 12 & 13 \\
\hline & Max Crane Wire Tension [kN] & 761.79 & 895.37 & 970.9 & 1005.2 & 1067.9 & 1096.7 & 1018 & 995.36 & 887.31 & 912.3 & 970.28 \\
\hline & Max Crane Tip Velocity [m/s] & 0.8152 & 1.4476 & 1.941 & 1.8372 & 2.0516 & 2.0585 & 1.692 & 1.6777 & 1.3431 & 1.513 & 1.583 \\
\hline
\end{tabular}


Table 6 Result for seabed landing with PHC (Hs = 3 m).

\begin{tabular}{|c|c|c|c|c|c|c|c|c|c|c|c|c|}
\hline \multirow{3}{*}{$165 \mathrm{deg}$} & $\mathrm{Tz}$ & 3 & 4 & 5 & 6 & 7 & 8 & 9 & 10 & 11 & 12 & 13 \\
\hline & Max Crane Wire Tension [kN] & 778.35 & 805.01 & 871.1 & 926.55 & 1041.5 & 1154.6 & 1075.4 & 1074.2 & 1110.7 & 1060.7 & 1154.1 \\
\hline & Max Crane Tip Velocity [m/s] & 0.60561 & 0.6655 & 0.8235 & 0.8312 & 1.7551 & 2.833 & 2.7831 & 2.3799 & 2.1275 & 1.8926 & 2.2877 \\
\hline \multirow{3}{*}{$180 \mathrm{deg}$} & $\mathrm{Tz}$ & 3 & 4 & 5 & 6 & 7 & 8 & 9 & 10 & 11 & 12 & 13 \\
\hline & Max Crane Wire Tension [kN] & 778.15 & 793.61 & 848.22 & 928.38 & 1071.1 & 1149.8 & 1061.1 & 1085.1 & 1017.4 & 969 & 1044.9 \\
\hline & Max Crane Tip Velocity [m/s] & 0.6065 & 0.6501 & 0.7398 & 0.8721 & 1.5476 & 2.1886 & 2.1362 & 1.8868 & 1.8904 & 1.6189 & 1.9381 \\
\hline \multirow{3}{*}{$195 \mathrm{deg}$} & $\mathrm{Tz}$ & 3 & 4 & 5 & 6 & 7 & 8 & 9 & 10 & 11 & 12 & 13 \\
\hline & Max Crane Wire Tension [kN] & 778.599 & 790.74 & 828.47 & 991.43 & 1190.7 & 1211.8 & 1145.5 & 1137.7 & 991.25 & 1060.4 & 1098.7 \\
\hline & Max Crane Tip Velocity [m/s] & 0.61257 & 0.642 & 0.6914 & 1.0844 & 2.1816 & 2.7569 & 2.3948 & 2.1726 & 1.4972 & 1.9216 & 2.2989 \\
\hline
\end{tabular}

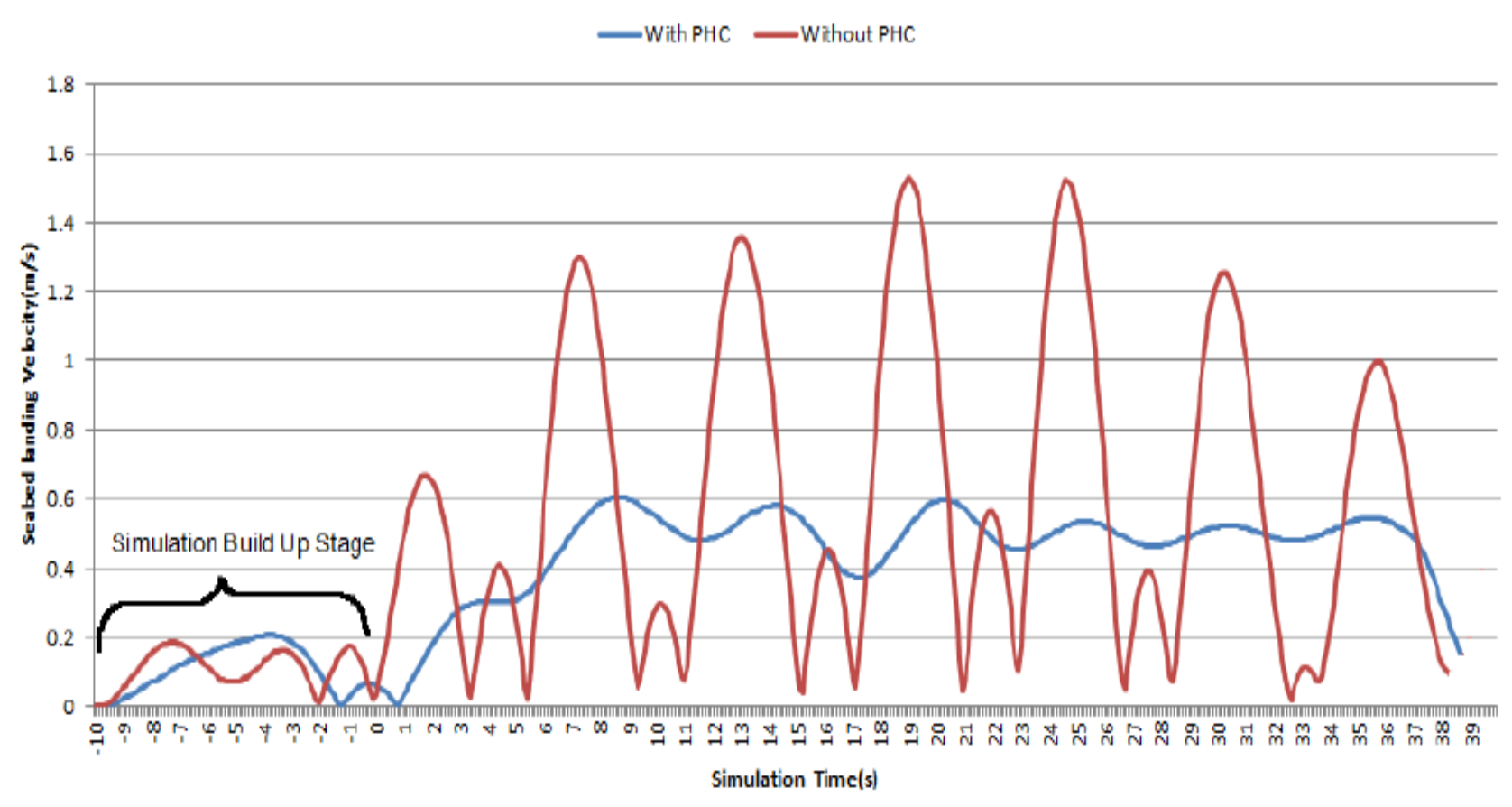

Fig. 8 Time history graph showing seabed landing velocity with and without PHC (Hs = 3 m).

\subsubsection{Seabed Landing Result}

During this phase of operation apart from maximum crane wire tension we are also interested to know the maximum crane tip velocity and the landing velocity of manifold on the seabed. The results are given in Tables 5 and 6:
On comparing maximum crane wire tension of Tables 1 and 5 we find that values in Table 5 are much smaller than values in Table 1 (hence also smaller than MBL). This indicates that crane wires and other lifting slings must be designed for splash zone operation.

In addition, the main reason of using PHC for seabed 
landing is to reduce the landing velocity of the structure on the seabed; which ultimately leads to reduction in the crane tip motions and velocities. On comparing the maximum crane tip velocity from Tables 5 and 6, we can deduce that for lower Tz values PHC reduces the maximum crane tip velocity. This indicates that PHC has higher efficiency at lower periods. Fig. 8 compares the seabed landing velocity of the manifold with and without PHC.

Fig. 8 depicts that during seabed landing of the manifold without PHC, the fluctuations in the landing velocities are large as compared to the landing velocity with PHC. Hence, for this phase of offshore lifting PHC reduces both, the maximum landing velocity and variations in the velocity by keeping payload at constant velocity thereby rendering its utility.

\section{Conclusion}

Based on the discussion of results in section 3 of this manuscript various conclusions are drawn:

(a) During offshore lifting operation, the maximum tension in crane wire and slings occurs for splash zone. Also during this phase the payload and hoisting system experiences the highest force variations due to transient hydrodynamic effects.

(b) PHC leads to reduction in tensions in crane wire and lifting slings. In other words PHC reduces dynamic loads on the hoisting system.

(c) The chances of slack slings is reduced by the use of PHC. However, even if slack slings occur with PHC the piston rod of PHC extends to compensate this removal of slack. Furthermore, PHC absorbs the snap load resulting from the sling tautening process; thereby protecting the hoisting system from huge snap forces.

(d) For the seabed landing operation PHC leads to reduction in maximum crane tip (heaving) velocities and landing speed of structure. PHC also reduces the variations in landing velocity by keeping the payload at constant velocity, hence abstaining hoisting system from huge dynamic accelerations and forces.

(e) PHC has highest efficiency at low Tz periods and with increasing wave period PHC becomes less efficient.

\section{References}

[1] Nam, B. W., Hong, S. Y., Kim, Y. S., and Kim, J. W. 2013. "Effects of Passive and Active Heave Compensators on Deepwater Lifting Operation.” International Journal of Offshore and Polar Engineering (23): 33-7.

[2] Det Norske Veritas. 2011. "Standard for Certification No. 2.22, Lifting Appliances.” Oslo.

[3] Martinsen, T., and Totland, A. 2012. The Engineers Guide, Second Edition. Safelink AS, Norway: 68, 70-5.

[4] Ernst-B. Johansen AS. Passive Heave Compensation-Cranemaster. http://www.cranemaster.no/cranemaster-products

[5] Det Norske Veritas. 2011. "Recommended Practice H-103, Modelling and Analysis of Marine Operations.” Oslo, Norway.

[6] Herdzik, J. 2014. "Utilization of an Active and/or Passive Heave Compensation in the Equipment of Dynamic Positioning Vessels.” Journal of KONES Powertrain and Transport (21): 89-95.

[7] Martinsen, T., and Totland, A. 2013.User Manual Second Edition, Safelink AS, Norway: 16.

[8] Cranemaster (Ernst-B. Johansen AS). 2012. "The Engineering Guide, Document number: EG-1002-A.” Norway: 3.

[9] Orcaflex Excel Spreadsheet. http://www.orcina.com/SoftwareProducts/OrcaFlex/Docu mentation/Help/Content/html/Post-processing,OrcaFlexS preadsheet.htm. 
Appendix: Post-Processing Excel Spreadsheet Used in Analysis.

\begin{tabular}{|c|c|c|c|c|c|c|c|c|c|c|c|}
\hline \multicolumn{12}{|c|}{ FOR 165 DEGREE; $\mathrm{Hs}=3 \mathrm{~m}$} \\
\hline \begin{tabular}{|c|} 
Crane Wire \\
Tension \\
[max. kN]
\end{tabular} & $\begin{array}{c}\text { Crane Wire } \\
\text { Tension } \\
\text { [min. kN] }\end{array}$ & $\begin{array}{l}\text { Delete } \\
\text { Max. }\end{array}$ & $\begin{array}{l}\text { Delete } \\
\text { Min. }\end{array}$ & $\begin{array}{l}\text { Fltd. } \\
\text { Max } \\
\text { Crane } \\
\text { Wire }\end{array}$ & $\begin{array}{c}\text { Fltd. } \\
\text { Min } \\
\text { Crane } \\
\text { Wire }\end{array}$ & \multicolumn{2}{|c|}{$\begin{array}{l}\text { Statistical Post- } \\
\text { Processing }\end{array}$} & \multicolumn{2}{|c|}{ Gumble } & filename; & $\mathrm{Tz}$ \\
\hline 1423.2 & 244.7 & 1423.2 & 244.7 & 1423.2 & 244.7 & Raw Max & 3388.6 & $\operatorname{Max}$ & & Case_A_01.dat & 3 \\
\hline 2054.5 & 7.8 & 2054.5 & 7.8 & 2054.5 & 7.8 & Raw Min & 0.0 & Median & 1591.7 & Case_A_02.dat & \\
\hline 3388.6 & 0.0 & & & & & Fltd Max & 2054.5 & StdDev & 254.4 & Case_A_03.dat & \\
\hline 2130.5 & 0.0 & 2130.5 & & & & Fltd Min & 0.4 & Beta & 198.4 & Case_A_04.dat & \\
\hline 1591.7 & 1.8 & 1591.7 & 1.8 & 1591.7 & 1.8 & Ave Max & 1684.6 & Mode, $\mu$ & 1519.0 & Case_A_05.dat & \\
\hline 1918.0 & 0.4 & 1918.0 & 0.4 & 1918.0 & 0.4 & Ave Min & 56.1 & ExMax & 2108.2 & Case_A_06.dat & \\
\hline 1857.5 & 2.0 & 1857.5 & 2.0 & 1857.5 & 2.0 & & & Min & & Case_A_07.dat & \\
\hline 2229.3 & 0.0 & 2229.3 & & & & & & Median & 3.9 & Case_A_08.dat & \\
\hline 1866.7 & 0.0 & 1866.7 & & & & PE & $95 \%$ & StdDev & 96.0 & Case_A_09.dat & \\
\hline 2337.2 & 0.0 & 2337.2 & & & & & & Beta & 74.9 & Case_A_010.dat & \\
\hline 1496.6 & 3.9 & 1496.6 & 3.9 & 1496.6 & 3.9 & & & Mode, $\mu$ & -23.5 & Case_A_011.dat & \\
\hline 1450.4 & 132.0 & 1450.4 & 132.0 & 1450.4 & 132.0 & & & cted Min. & -105.7 & Case_A_012.dat & \\
\hline 1478.3 & 6.1 & 1478.3 & 6.1 & 1478.3 & 6.1 & Raw Max & 1992.0 & $\operatorname{Max}$ & & Case_A_013.dat & 4 \\
\hline 1437.7 & 101.4 & 1437.7 & 101.4 & 1437.7 & 101.4 & Raw Min & 0.6 & Median & 1608.8 & Case_A_014.dat & \\
\hline 1212.2 & 80.8 & 1212.2 & 80.8 & 1212.2 & 80.8 & Fltd Max & 1856.0 & StdDev & 209.2 & Case_A_015.dat & \\
\hline 1856.0 & 0.9 & 1856.0 & 0.9 & 1856.0 & 0.9 & Fltd Min & 0.9 & Beta & 163.1 & Case_A_016.dat & \\
\hline 1650.5 & 6.2 & 1650.5 & 6.2 & 1650.5 & 6.2 & Ave Max & 1586.3 & Mode, $\mu$ & 1549.0 & Case_A_017.dat & \\
\hline 1598.3 & 3.6 & 1598.3 & 3.6 & 1598.3 & 3.6 & Ave Min & 58.0 & ExMax & 2033.5 & Case_A_018.dat & \\
\hline 1784.3 & 5.0 & 1784.3 & 5.0 & 1784.3 & 5.0 & & & Min & & Case_A_019.dat & \\
\hline 1992.0 & 0.6 & & & & & & & Median & 7.9 & Case_A_020.dat & \\
\hline 1608.8 & 210.7 & 1608.8 & 210.7 & 1608.8 & 210.7 & PE & $95 \%$ & StdDev & 82.0 & Case_A_021.dat & \\
\hline 1839.9 & 8.8 & 1839.9 & 8.8 & 1839.9 & 8.8 & & & Beta & 63.9 & Case_A_022.dat & \\
\hline 1311.4 & 207.0 & 1311.4 & 207.0 & 1311.4 & 207.0 & & & Mode, $\mu$ & -15.5 & Case_A_023.dat & \\
\hline 1671.6 & 7.9 & 1671.6 & 7.9 & 1671.6 & 7.9 & & & cted Min. & -85.7 & Case_A_024.dat & \\
\hline 1844.1 & 4.0 & 1844.1 & 4.0 & 1844.1 & 4.0 & Raw Max & 2244.1 & Max & & Case_A_025.dat & 5 \\
\hline 1700.1 & 6.1 & 1700.1 & 6.1 & 1700.1 & 6.1 & Raw Min & 2.3 & Median & 1720.1 & Case_A_026.dat & \\
\hline 1477.2 & 120.3 & 1477.2 & 120.3 & 1477.2 & 120.3 & Fltd Max & 1844.1 & StdDev & 193.5 & Case_A_027.dat & \\
\hline 1356.7 & 105.9 & 1356.7 & 105.9 & 1356.7 & 105.9 & Fltd Min & 4.0 & Beta & 150.9 & Case_A_028.dat & \\
\hline 1824.4 & 20.6 & 1824.4 & 20.6 & 1824.4 & 20.6 & Ave Max & 1660.8 & Mode, $\mu$ & 1664.8 & Case_A_029.dat & \\
\hline 1838.8 & 9.6 & 1838.8 & 9.6 & 1838.8 & 9.6 & Ave Min & 74.1 & ExMax & 2113.0 & Case_A_030.dat & \\
\hline 1354.0 & 141.5 & 1354.0 & 141.5 & 1354.0 & 141.5 & & & Min & & Case_A_031.dat & \\
\hline 2244.1 & 3.7 & & 3.7 & & & & & Median & 60.3 & Case_A_032.dat & \\
\hline 1740.2 & 224.7 & 1740.2 & 224.7 & 1740.2 & 224.7 & PE & $95 \%$ & StdDev & 75.9 & Case_A_033.dat & \\
\hline 1683.5 & 99.9 & 1683.5 & 99.9 & 1683.5 & 99.9 & & & Beta & 59.2 & Case_A_034.dat & \\
\hline 2080.7 & 2.3 & 2080.7 & & & & & & Mode, $\mu$ & 38.6 & Case_A_035.dat & \\
\hline 1788.9 & 8.8 & 1788.9 & 8.8 & 1788.9 & 8.8 & & & cted Min. & -26.4 & Case_A_036.dat & \\
\hline 1642.6 & 286.4 & 1642.6 & 286.4 & 1642.6 & 286.4 & Raw Max & 1967.4 & Max & & Case_A_037.dat & 6 \\
\hline 1000.4 & 533.0 & 1000.4 & 533.0 & 1000.4 & 533.0 & Raw Min & 7.4 & Median & 1429.4 & Case_A_038.dat & \\
\hline 1576.0 & 256.3 & 1576.0 & 256.3 & 1576.0 & 256.3 & Fltd Max & 1642.6 & StdDev & 238.3 & Case_A_039.dat & \\
\hline 1297.5 & 327.7 & 1297.5 & 327.7 & 1297.5 & 327.7 & Fltd Min & 115.4 & Beta & 185.8 & Case_A_040.dat & \\
\hline 1608.9 & 129.6 & 1608.9 & 129.6 & 1608.9 & 129.6 & Ave Max & 1363.5 & Mode, $\mu$ & 1361.3 & Case_A_041.dat & \\
\hline 1052.7 & 439.2 & 1052.7 & 439.2 & 1052.7 & 439.2 & Ave Min & 292.1 & ExMax & 1913.2 & Case_A_042.dat & \\
\hline 1786.5 & 7.4 & 1786.5 & & & & & & Min & & Case_A_043.dat & \\
\hline 1490.7 & 172.1 & 1490.7 & 172.1 & 1490.7 & 172.1 & & & Median & 271.3 & Case_A_044.dat & \\
\hline 1107.3 & 465.6 & 1107.3 & 465.6 & 1107.3 & 465.6 & PE & $95 \%$ & StdDev & 146.7 & Case_A_045.dat & \\
\hline 1381.7 & 195.3 & 1381.7 & 195.3 & 1381.7 & 195.3 & & & Beta & 114.4 & Case_A_046.dat & \\
\hline 1967.4 & 9.4 & & 9.4 & & & & & Mode, $\mu$ & 229.4 & Case_A_047.dat & \\
\hline 1477.1 & 115.4 & 1477.1 & 115.4 & 1477.1 & 115.4 & & & cted Min. & 103.9 & Case_A_048.dat & \\
\hline
\end{tabular}




\begin{tabular}{|c|c|c|c|c|c|c|c|c|c|c|c|}
\hline $\begin{array}{c}\text { Crane Wire } \\
\text { Tension } \\
{[\max . \mathrm{kN}]}\end{array}$ & $\begin{array}{c}\text { Crane Wire } \\
\text { Tension } \\
\text { [min. kN] }\end{array}$ & $\begin{array}{l}\text { Dele te } \\
\text { Max. }\end{array}$ & $\begin{array}{l}\text { Delete } \\
\text { Min. }\end{array}$ & $\begin{array}{l}\text { Fltd. } \\
\text { Max } \\
\text { Crane } \\
\text { Wire }\end{array}$ & $\begin{array}{l}\text { Fltd. } \\
\text { Min } \\
\text { Crane } \\
\text { Wire }\end{array}$ & \multicolumn{2}{|c|}{$\begin{array}{l}\text { Statistical Post- } \\
\text { Processing }\end{array}$} & \multicolumn{2}{|c|}{ Gumble } & filename; & $\mathrm{Tz}$ \\
\hline 997.7 & 435.9 & 997.7 & 435.9 & 997.7 & 435.9 & Raw Max & \multirow{2}{*}{$\begin{array}{c}1740.0 \\
9.0\end{array}$} & Max & \multirow{2}{*}{1241.8} & \multirow{2}{*}{ Case_A_049.dat } & 7 \\
\hline 1499.0 & 294.1 & 1499.0 & 294.1 & 1499.0 & 294.1 & \multirow{5}{*}{$\begin{array}{l}\text { Raw Min } \\
\text { Fltd Max } \\
\text { Fltd Min } \\
\text { Ave Max } \\
\text { Ave Min }\end{array}$} & & Median & & & \\
\hline 1239.1 & 377.6 & 1239.1 & 377.6 & 1239.1 & 377.6 & & 1499.0 & StdDev & 142.1 & \multicolumn{2}{|l|}{1 Case_A_051.dat } \\
\hline 1081.5 & 354.6 & 1081.5 & 354.6 & 1081.5 & 354.6 & & 47.4 & Beta & 110.8 & \multirow{2}{*}{\multicolumn{2}{|c|}{$\begin{array}{l}\text { Case_A_052.dat } \\
\text { Case_A_053.dat }\end{array}$}} \\
\hline 1309.8 & 47.4 & 1309.8 & 47.4 & 1309.8 & 47.4 & & 1235.0 & Mode, $\mu$ & 1201.2 & & \\
\hline 1740.0 & 388.3 & & 388.3 & & & & 297.8 & ExMax & 1530.4 & Case_A_054.dat & \\
\hline 11524 & 251.5 & 1152.4 & 251.5 & 1152.4 & 251.5 & & & Min & & Case_A_055.dat & \\
\hline 1244.5 & 452.7 & 1244.5 & 452.7 & 1244.5 & 452.7 & & & Median & 319.1 & Case_A_056.dat & \\
\hline 1359.8 & 136.0 & 1359.8 & 136.0 & 1359.8 & 136.0 & $\mathrm{PE}$ & $95 \%$ & StdDev & 127.4 & Case_A_057.dat & \\
\hline 1278.6 & 344.1 & 1278.6 & 344.1 & 1278.6 & 344.1 & & & Beta & 99.3 & Case_A_058.dat & \\
\hline 1591.7 & 9.0 & 1591.7 & & & & & & Mode, $\mu$ & 282.7 & Case_A_059.dat & \\
\hline 1187.3 & 284.0 & 1187.3 & 284.0 & 1187.3 & 284.0 & & $\mathrm{Ep}$ & acted $\mathrm{Min}$ & 173.7 & Case_A_060.dat & \\
\hline 994.4 & 432.5 & 994.4 & 432.5 & 994.4 & 432.5 & Raw Max & 1613.8 & $\operatorname{Max}$ & & Case_A_061.dat & 8 \\
\hline 1578.4 & 247.7 & 1578.4 & 247.7 & 1578.4 & 247.7 & Raw Mm & 23.8 & Median & 1073.1 & Case_A_062.dat & \\
\hline 1502.8 & 253.5 & 1502.8 & 253.5 & 1502.8 & 253.5 & Fltd Max & 1578.4 & StdDev & 208.6 & Case_A_003.dat & \\
\hline 1118.7 & 225.5 & 1118.7 & 225.5 & 1118.7 & 225.5 & Fitd $\mathrm{Min}$ & 225.5 & Beta & 162.6 & Case_A_064.dat & \\
\hline 991.7 & 533.5 & 991.7 & 533.5 & 991.7 & 533.5 & Ave Max & 1139.1 & Mode, $\mu$ & 1013.5 & Case_A_005.dat & \\
\hline 1053.0 & 463.2 & 1053.0 & 463.2 & 1053.0 & 463.2 & Ave Mm & 395.2 & ExMax & 1496.6 & Case_A_060.dat & \\
\hline 1073.1 & 339.7 & 1073.1 & 339.7 & 1073.1 & 339.7 & & & Min & & Case_A_067.dat & \\
\hline 1171.2 & 406.7 & 1171.2 & 406.7 & 1171.2 & 406.7 & & & Median & 432.5 & Case_A_068.dat & \\
\hline 1087.9 & 496.5 & 1087.9 & 496.5 & 1087.9 & 496.5 & $\mathrm{PE}$ & $95 \%$ & StdDev & 111.2 & Case_A_009.dat & \\
\hline 997.5 & 443.2 & 997.5 & 443.2 & 997.5 & 443.2 & & & Beta & 86.7 & Case_A_070.dat & \\
\hline 962.0 & 505.2 & 962.0 & 505.2 & 962.0 & 505.2 & & & Mode, $\mu$ & 400.7 & Case_A_071.dat & \\
\hline 1613.8 & 23.8 & & & & & & Exp & acted $\mathrm{Mm}$. & 305.6 & Case_A_072.dat & \\
\hline 1000.5 & 530.4 & 1000.5 & 530.4 & 1000.5 & 530.4 & Raw Max & 1300.9 & Max & & Case_A_073.dat & 9 \\
\hline 1072.3 & 474.4 & 10723 & 474.4 & 1072.3 & 474.4 & Raw Mm & 110.9 & Median & 1036.4 & Case_A_074.dat & \\
\hline 1300.9 & 403.3 & & 403.3 & & & Fltd Max & 1237.1 & StdDev & 107.9 & Case_A_075.dat & \\
\hline 1133.6 & 255.0 & 1133.6 & 255.0 & 1133.6 & 255.0 & Fltd Min & 215.5 & Beta & 84.1 & Case_A_076.dat & \\
\hline 995.9 & 493.8 & 995.9 & 493.8 & 995.9 & 493.8 & Ave Max & 1063.2 & Mode, $\mu$ & 1005.5 & Case_A_077.dat & \\
\hline 978.8 & 466.7 & 978.8 & 466.7 & 978.8 & 466.7 & Ave Min & 430.1 & ExMax & 1255.4 & Case_A_078.dat & \\
\hline 1149.4 & 459.0 & 1149.4 & 459.0 & 1149.4 & 459.0 & & & Min & & Case_A_079.dat & \\
\hline 923.3 & 576.5 & 923.3 & 576.5 & 923.3 & 576.5 & & & Median & 470.6 & Case_A_OSO.dat & \\
\hline 954.6 & 484.0 & 954.6 & 484.0 & 954.6 & 484.0 & $\mathrm{PE}$ & $95 \%$ & StdDev & 118.5 & Case_A_081.dat & \\
\hline 1237.1 & 215.5 & 1237.1 & 215.5 & 1237.1 & 215.5 & & & Beta & 92.4 & Case_A_082.dat & \\
\hline 1186.0 & 346.0 & 1186.0 & 346.0 & 1186.0 & 346.0 & & & Mode, $\mu$ & 436.7 & Case_A_083.dat & \\
\hline 1198.2 & 110.9 & 1198.2 & & & & & Epp & acted $\mathrm{Mm}$ & 335.3 & Case_A_084.dat & \\
\hline 907.6 & 599.3 & 907.6 & 599.3 & 907.6 & 599.3 & Raw Max & 1214.1 & $\operatorname{Mgx}$ & & Case_A_085.dat & 10 \\
\hline 1149.2 & 354.6 & 1149.2 & & & & Raw Min & 354.6 & Median & 1014.8 & Case_A_086.dat & \\
\hline 962.7 & 498.8 & 962.7 & 498.8 & 962.7 & 498.8 & Fltd Max & 1068.8 & StdDev & 56.9 & Case_A_087.dat & \\
\hline 918.1 & 481.6 & 918.1 & 481.6 & 918.1 & 481.6 & Fltd Min & 400.1 & Beta & 44.4 & Case_A_088.dat & \\
\hline 1042.9 & 632.6 & 1042.9 & 632.6 & 1042.9 & 632.6 & Ave Max & 995.0 & Mode, $\mu$ & 998.6 & Case_A_089.dat & \\
\hline 1214.1 & 502.0 & & 502.0 & & & Ave Min & 522.0 & ExMax & 1130.4 & Case_A_090.dat & \\
\hline 1068.8 & 400.1 & 1068.8 & 400.1 & 1068.8 & 400.1 & & & Min & & Case_A_091.dat & \\
\hline 1021.2 & 470.4 & 1021.2 & 470.4 & 1021.2 & 470.4 & & & Median & 508.8 & Case_A_092.dat & \\
\hline 1044.7 & 525.8 & 1044.7 & 525.8 & 1044.7 & 525.8 & $\mathrm{PE}$ & $95 \%$ & StdDev & 70.7 & Case_A_093.dat & \\
\hline 1028.8 & 492.3 & 1028.8 & 492.3 & 1028.8 & 492.3 & & & Beta & 55.1 & Case_A_094.dat & \\
\hline 1008.4 & 518.8 & 1008.4 & 518.8 & 1008.4 & 518.8 & & & Mode, $\mu$ & 488.6 & Case_A_095.dat & \\
\hline 946.4 & 600.3 & 946.4 & 600.3 & 946.4 & 600.3 & & Epp & acted $\mathrm{Mm}$ & 428.2 & Case_A_096.dat & \\
\hline 1001.1 & 628.6 & 1001.1 & 628.6 & 1001.1 & 628.6 & Raw Max & 1131.7 & $\operatorname{Max}$ & & Case_A_097.dat & 11 \\
\hline 977.8 & 501.8 & 977.8 & 501.8 & 977.8 & 501.8 & Raw Mm & 427.4 & Median & 997.0 & Case_A_098.dat & \\
\hline 997.0 & 497.3 & 997.0 & 497.3 & 997.0 & 497.3 & Fltd Max & 1071.2 & StdDev & 37.6 & Case_A_099.dat & \\
\hline 941.8 & 580.5 & 941.8 & 580.5 & 941.8 & 580.5 & Fltd Min & 486.5 & Beta & 29.3 & Case_A_0100.da & \\
\hline 1049.1 & 558.5 & 1049.1 & 558.5 & 1049.1 & 558.5 & Ave Max & 1003.2 & Mode, $\mu$ & 986.3 & Case_A_0101.da & \\
\hline 976.9 & 554.2 & 976.9 & 554.2 & 976.9 & 554.2 & Ave Min & 554.5 & ExMax & 1073.3 & Case_A_0102.da & \\
\hline 1071.2 & 590.5 & 1071.2 & 590.5 & 1071.2 & 590.5 & & & Min & & Case_A_0103.da & \\
\hline 999.2 & 592.1 & 999.2 & 592.1 & 999.2 & 592.1 & & & Median & 558.5 & Case_A_0104.da & \\
\hline 1043.9 & 486.5 & 1043.9 & 486.5 & 1043.9 & 486.5 & $\mathrm{PE}$ & $95 \%$ & StdDev & 51.0 & Case_A_0105.da & \\
\hline 980.0 & 497.7 & 980.0 & 497.7 & 980.0 & 497.7 & & & Beta & 39.8 & Case_A_0106.da & \\
\hline 1131.7 & 427.4 & & & & & & & Mode, $\mu$ & 543.9 & Case_A_0107.da & \\
\hline 996.9 & 611.6 & 996.9 & 611.6 & 996.9 & 611.6 & & & cted $\mathrm{Mm}$ & 500.2 & Case_A_0108.da & \\
\hline
\end{tabular}




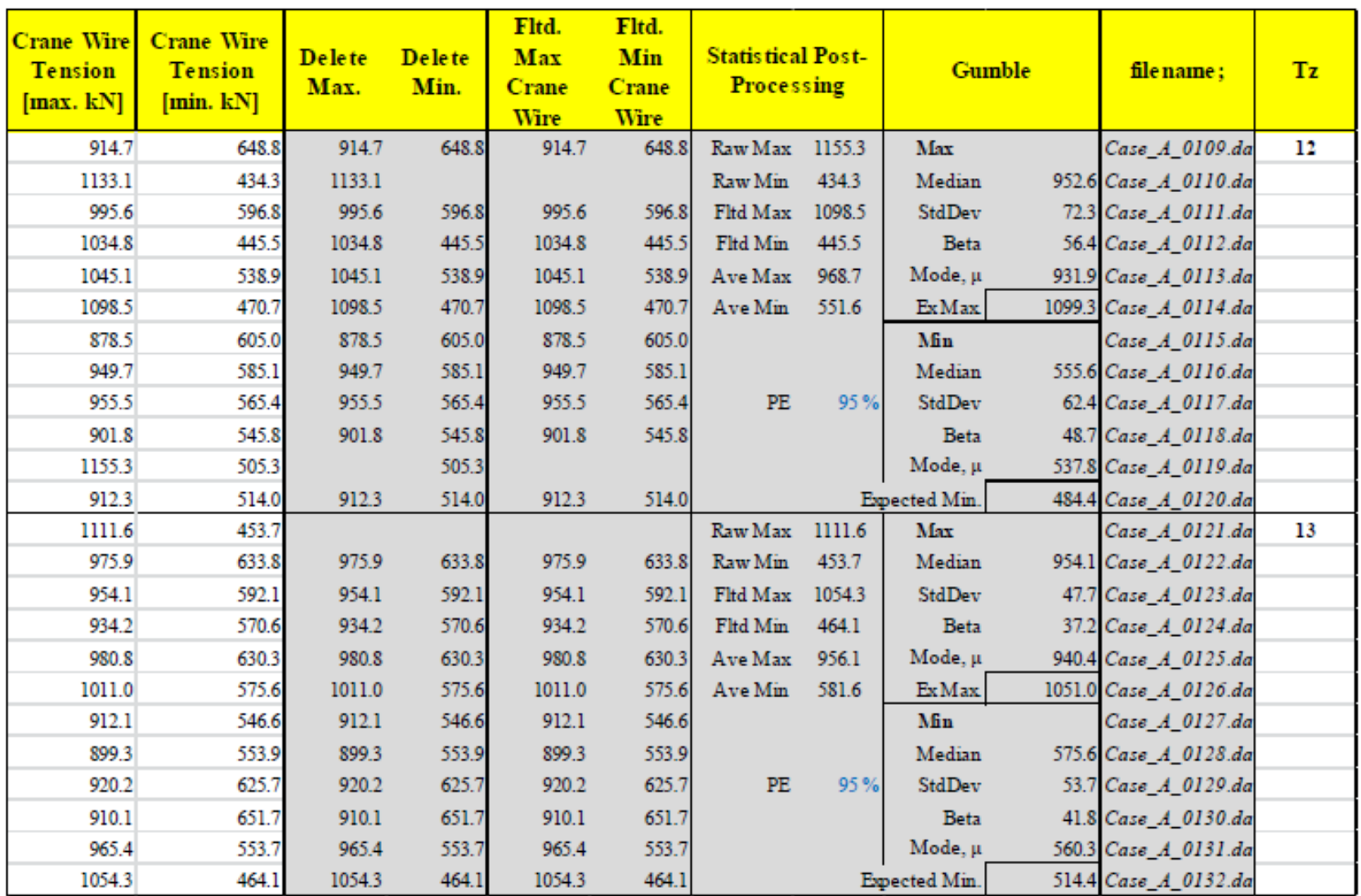

\section{SUMMARY OF RESULTS:}

\begin{tabular}{|c|c|c|c|c|c|c|c|c|c|c|c|}
\hline $\mathrm{Tz}$ & 3 & 4 & 5 & 6 & 7 & 8 & 9 & 10 & 11 & 12 & 13 \\
\hline Raw Max & 3388.6 & 1992.0 & 2244.1 & 1967.4 & 1740.0 & 1613.8 & 1300.9 & 1214.1 & 1131.7 & 1155.3 & 1111.6 \\
\hline Raw Min & 0.0 & 0.6 & 2.3 & 7.4 & 9.0 & 23.8 & 110.9 & 354.6 & 427.4 & 434.3 & 453.7 \\
\hline Fltd Max & 2054.5 & 1856.0 & 1844.1 & 1642.6 & 1499.0 & 1578.4 & 1237.1 & 1068.8 & 1071.2 & 1098.5 & 1054.3 \\
\hline Fltd Min & 0.4 & 0.9 & 4.0 & 115.4 & 47.4 & 225.5 & 215.5 & 400.1 & 486.5 & 445.5 & 464.1 \\
\hline Ave Max & 1684.6 & 1586.3 & 1660.8 & 1363.5 & 1235.0 & 1139.1 & 1063.2 & 995.0 & 1003.2 & 968.7 & 956.1 \\
\hline Ave Min & 56.1 & 58.0 & 74.1 & 292.1 & 297.8 & 395.2 & 430.1 & 522.0 & 554.5 & 551.6 & 581.6 \\
\hline Exp. Max. & 2108.2 & 2033.5 & 2113.0 & 1913.2 & 1530.4 & 1496.6 & 1255.4 & 1130.4 & 1073.3 & 1099.3 & 1051.0 \\
\hline Exp. Min. & -105.7 & -85.7 & -26.4 & 103.9 & 173.7 & 305.6 & 335.3 & 428.2 & 500.2 & 484.4 & 514.4 \\
\hline
\end{tabular}

Note: .dat file under column filename are the simulations created on Orcaflex software.

Appendix: Abbreviation List

PHC: $\quad$ Passive Heave Compensator

Hs: $\quad$ Significant wave height

Tz: $\quad$ Zero-up crossing period

$\Psi$ : $\quad$ Dynamic factor

SWL: $\quad$ Safe Working Load

AHC: $\quad$ Active Heave Compensator

$V c$ : Hoisting velocity

$V r: \quad$ Relative velocity between load and hook at the time of pick up 


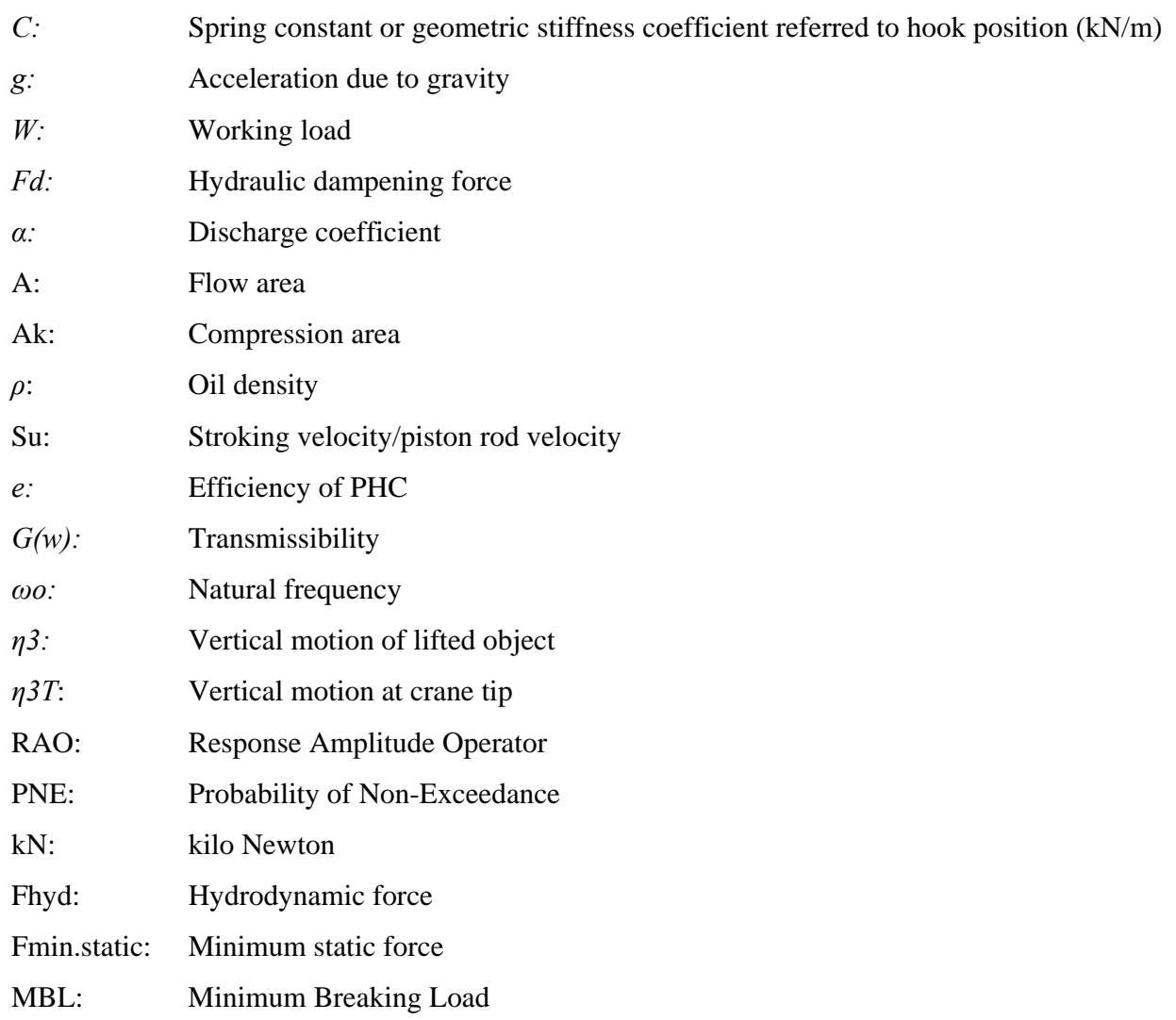

